\title{
Analisis Pengaturan Quarter-Car Active Suspension Menggunakan Neuro-Fuzzy Adaptif PID Control
}

\author{
Aprildy Randy Andrew Ferdinandus ${ }^{1}$, Santo Junital Bumbungan ${ }^{2}$ \\ ${ }^{1}$ Fakultas Teknik Universitas Sariputra Indonesia Tomohon, ${ }^{2}$ Fakultas Teknik Universitas Sariputra Indonesia \\ Tomohon
}

aprildy.ferdinandus@unsrittomohon.ac.id,aprildy.ferdinandus@gmail.com

\begin{abstract}
Car as a vehicle has a suspension on the wheels that connect the body with the road surface. The suspension is arranged in such way as to ensure the comfort in driving even on uneven road surfaces or damaged road surfaces. Because of the changes in road surface, it is very important to make adjustments to the suspension. The car suspension is adjusted using Neuro-Fuzzy Adaptive PID Control System so that the performance of the suspension can be improved in ensuring user comfort by reducing vibrations in the car body. Improved performance can be seen in the results of the suspension setting, which can suppress the movement of the car body because of the change in road surface more than $80 \%$.
\end{abstract}

Keyword - neuro-fuzzy pid, active suspension, quarter-car

Abstrak - Mobil sebagai kendaraan bermotor memiliki suspensi pada rodanya yang menghubungkan badan mobil dan permukaan jalan. Suspensi diatur sedemikian rupa sehingga dapat memastikan kenyamanan dalam berkendara walaupun melewati permukaan jalan yang tidak rata ataupun permukaan jalan yang rusak. Dengan adanya perubahan pada permukaan jalan, adalah sangat penting untuk melakukan pengaturan pada suspensi. Suspensi mobil diatur dengan menggunakan sistem pengaturan Neuro-Fuzzy Adaptif PID Control sehingga performansi dari suspensi dapat ditingkatkan dalam menjamin kenyamanan pengguna yaitu dengan mengurangi getaran pada badan mobil. Peningkatan performansi dapat dilihat pada hasil pengaturan suspensi yaitu dapat menekan pergerakan badan mobil terhadap perubahan permukaan jalan lebih dari $80 \%$.

Kata kunci - neuro-fuzzy pid, suspensi aktif, quarter-car

\section{PENDAHULUAN}

Dalam perkembangan sistem suspensi sekarang ini, sistem suspensi dapat dibagi dalam tiga bagian yaitu suspensi pasif, suspensi semi aktif dan suspensi aktif. Dalam performansinya suspensi semi aktif dan suspensi aktif lebih tinggi dibandingkan dengan suspensi pasif, hal ini dikarenakan suspensi semi aktif dan suspensi aktif dapat diatur dengan sistem pengaturan sehingga dapat menghadapi dan lebih menyesuaikan pada kondisi permukaan jalan yang tidak selalu bagus.

Dalam perkembangan penelitian sistem suspensi, upaya untuk mengatur suspensi aktif sering dilakukan dengan mempertimbangkan kondisi-kondisi yang ada juga dengan mengaplikasi berbagai metode sistem pengaturan. Du, Haiping, Zhang dan Nong meneliti pengaturan suspensi aktif yang memperhitungkan time delay pada aktuator dengan sistem pengaturan Hinf [1], Salem, M dan Aly
Ayman melakukan penelitian untuk mengatur sistem suspensi aktif menggunakan fuzzy logic control [2]. Pengaturan suspensi aktif quarter-car dilakukan juga oleh Priyandoko, $\mathrm{G}$ et al yaitu dengan menggunakan metode pengaturan skyhook adaptive neuro active force control [3]. A.R.A Ferdinandus yang adalah penulis artikel ini juga melakukan beberapa penelitian tentang pengaturan suspensi aktif sebelumnya antara lain penelitian tentang penggunaan sistem pengaturan neuro-fuzzy pid control pada plant suspensi aktif nonlinier [4], juga Youness, S.F dan Lobusov, E.C melakukan penelitian tentang suspensi aktif yang diatur menggunakan network control [5].

Pengaturan suspensi aktif dapat dilakukan secara sistem quarter-car (1 roda), sistem half-car (2 roda) dan sistem fullcar (4 roda). Penelitian yang ada akan menyesuaikan bentuk plant serta kondisi yang dihadapi baik itu perubahan permukaan jalan ataupun perubahan-perubahan parameter di dalam plant mobil. Ikenaga, S. et al meneliti pengaturan suspensi aktif secara model full-car [6]. Md Sam, Yahaya dan Osman, Johari meneliti pengaturan suspensi aktif dengan menggunakan pendekatan proporsional integral sliding mode [7].

Dalam penelitian ini digunakan sistem pengaturan NeuroFuzzy Adaptif PID Control untuk mengatur sistem suspensi aktif quarter-car yang dilakukan secara simulasi menggunakan program Simulink Matlab, pada akhirnya akan dilakukan analisis perbandingan hasil pengaturan dengan hasil dari open-loop sistem suspensi aktif.

\section{METODE PENELITIAN}

Dilakukan beberapa tahapan dalam penelitian ini seperti yang ditunjukkan pada gambar 1. Pada awalnya dilakukan identifikasi sistem suspensi aktif, setiap komponen yang ada di dalam suspensi termasuk dengan aktuator yang ada. Hasil identifikasi sistem akan digunakan untuk pemodelan pada program Simulink Matlab serta akan dilakukan penyesuaian-penyesuaian yang ada sesuai dengan kondisi yang ditetapkan. Tahapan selanjutnya adalah memodelkan sistem pengaturan Neuro-Fuzzy Adaptif PID Control pada Simulink Matlab. Nilai Kp, Ki dan Kd diuji coba untuk diambil range terbaik untuk setiap kemungkinan permukaan jalan yang akan dihadapi. Selanjutnya dilakukan simulasi terhadap open loop plant sistem suspensi serta simulasi 
terhadap sistem suspensi yang diatur oleh Neuro-Fuzzy Adaptif PID Control.

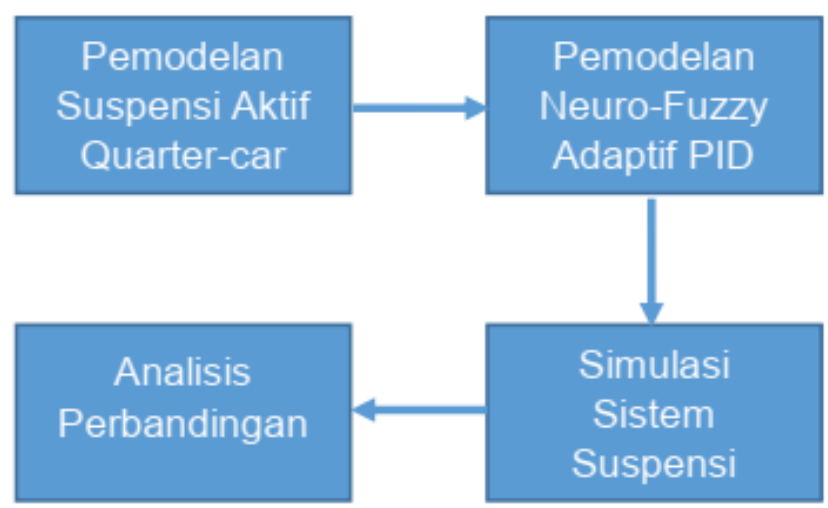

Gambar 1. Tahapan Penelitian.

\section{A. Suspensi Aktif Quarter-car}

Model mekanik suspensi aktif secara sistem quarter-car dapat dilihat pada gambar 2 .

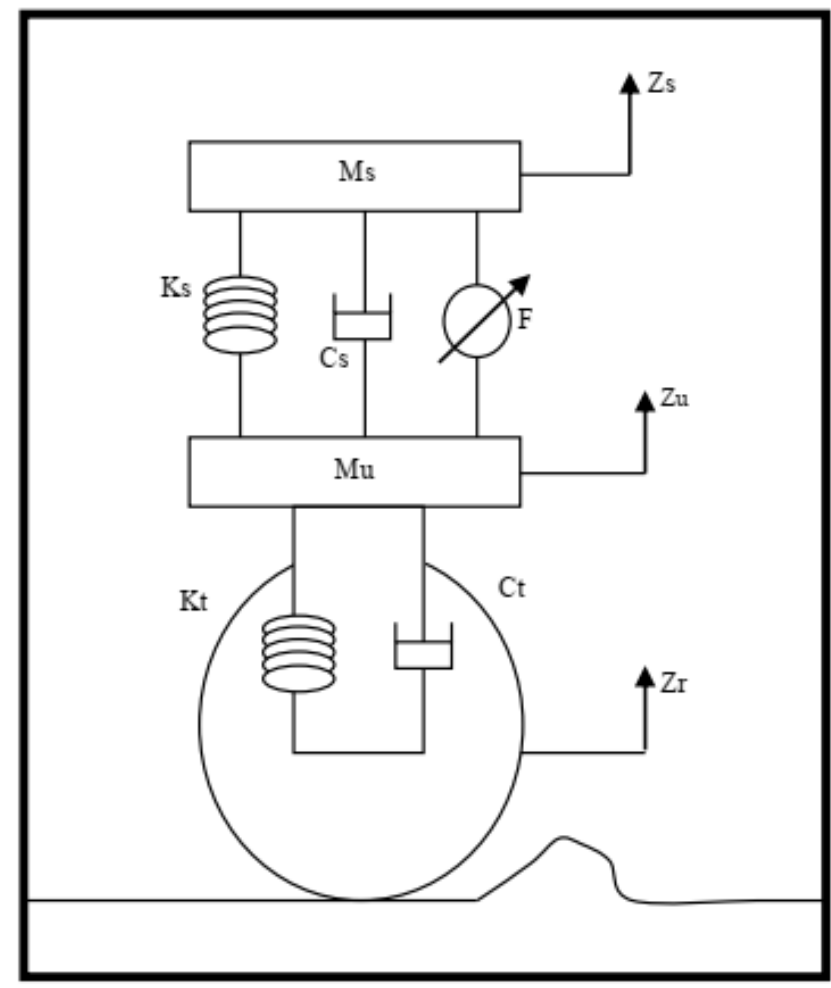

Gambar 2. Model Mekanik Suspensi Aktif Quarter-car

Dengan gambar model mekanik yang ada maka dilakukan pemodelan secara matematik untuk suspensi aktif quartercar (1 roda). Model matematik yang diturunkan dari gambar 2 ditunjukkan sebagai persamaan (1), (2) dan (3)

$$
\begin{gathered}
F k(z)=K Z+K n Z^{3} \\
F c(\dot{z})=C Z+C n \dot{Z}^{2} \operatorname{sgn}(\dot{Z}) \\
F=u
\end{gathered}
$$

Parameter-parameter dari sistem suspensi yang digunakan dalam model matematik suspensi ditunjukkan pada tabel 1, sehingga pada simulasi yang dilakukan, nilai-nilai yang dimasukkan adalah nilai-nilai parameter yang ada.

TABEL I

PARAMETER SUSPENSI

\begin{tabular}{ll}
\hline \hline Parameter & Nilai $($ SI $)$ \\
\hline $\mathrm{Ms}$ & $360 \mathrm{~kg}$ \\
$\mathrm{Mu}$ & $25 \mathrm{~kg}$ \\
$\mathrm{Cs}$ & $500 \mathrm{~N} \mathrm{~s} / \mathrm{m}$ \\
$\mathrm{Ks}$ & $1000 \mathrm{~N} / \mathrm{m}$ \\
$\mathrm{Ct}$ & 0 \\
$\mathrm{Kt}$ & $300000 \mathrm{~N} / \mathrm{m}$ \\
$\mathrm{Ap}$ & $0.0044 \mathrm{~m}^{2}$ \\
$\mathrm{Cdi}$ & 0.7 \\
$\alpha$ & $2.273 \mathrm{e} 9 \mathrm{~N} / \mathrm{m}^{5}$ \\
$\mathrm{w}$ & $0.008 \mathrm{~m}$ \\
$\mathrm{Ps}$ & $20684 \mathrm{kN} / \mathrm{m}^{2}$ \\
$\rho$ & 3500 \\
$\mathrm{Ctm}$ & $15 \mathrm{e}-12$ \\
\hline \hline
\end{tabular}

$\mathrm{kg}=$ Kilogram, $\mathrm{N}=$ Newton, $\mathrm{s}=$ second, $\mathrm{m}=$ meter, $\mathrm{kN}=$ kilo Newton

\section{B. Neuro-Fuzzy Adaptif PID}

Sistem pengaturan Neuro-Fuzzy Adaptif PID Control yang digunakan dalam penelitian ini adalah pengembangan dari sistem pengaturan PID yang membuat sistem pengaturan PID dapat mengatur sistem secara adaptif sesuai dengan sinyal error yang diterima dimana mekanisme adaptifnya diatur menggunakan metode gabungan dari Neural Netrowk dan Fuzzy Logic atau disebut Neuro-Fuzzy.

Sinyal error yang didapatkan dari selisih antara masukan dan keluaran dijadikan indikator masukan pada sistem Neuro-Fuzzy untuk bisa menentukan nilai Kp, Ki, Kd pada sistem pengaturan PID yang lebih baik untuk mengatur plant suspensi aktif.

Gambar 3 menunjukkan rancangan sistem pengaturan suspensi aktif quarter-car (1 roda) menggunakan sistem pengaturan Neuro-Fuzzy Adaptif PID Control.

Simulasi dilakukan dengan model suspensi di dalam program Simulink Matlab dengan memasukkan gangguan berupa perubahan permukaan jalan sebagai masukan gangguan pada plant sistem suspensi. Sistem pengaturan PID akan secara adaptif melakukan pengaturan pada suspensi aktif. 


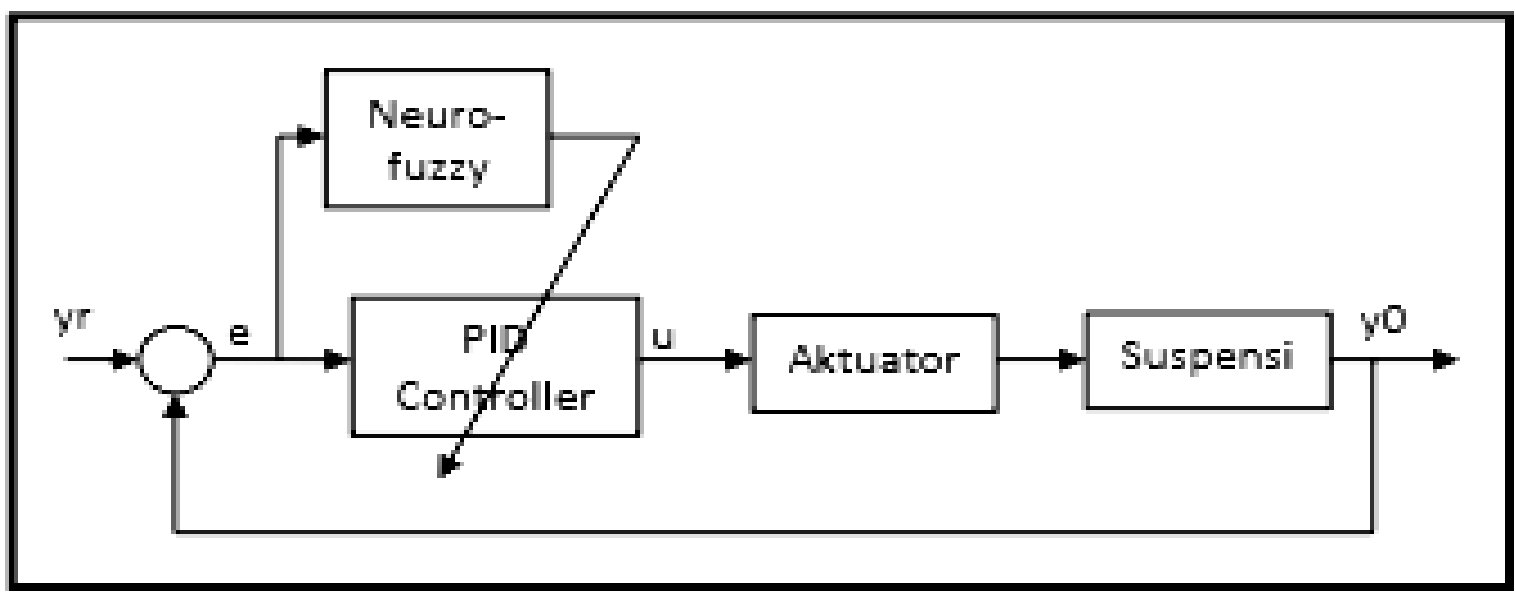

Gambar 3. Diagram Blok Pengaturan Suspensi Aktif Quarter-car Menggunakan Neuro-Fuzzy Adaptif PID control

\section{HASIL DAN PEMBAHASAN}

Simulasi dilakukan pada sistem suspensi aktif quarter-car secara open-loop tanpa sistem pengaturan dan dengan sistem pengaturan Neuro-Fuzzy Adaptif PID control. Pada gambar 4 menunjukkan respon keluaran dari suspensi tanpa sistem pengaturan. Dapat terlihat pada gambar 4 terdapat 3 buah garis berwarna biru, merah dan kuning di mana masing-masing warna mewakili ketinggian perubahan dari permukaan jalan (warna biru), roda kendaraan (warna merah) dan badan mobil (warna kuning). Dengan adanya gangguan setinggi $10 \mathrm{~cm}$ (garis biru pada gambar 4) maka badan mobil juga akan mengalami perubahan ketinggian setinggi $8 \mathrm{~cm}$ (garis kuning pada gambar 4) sedangkan jika sistem suspensi ditambahkan sistem pengaturan maka hasil respon sistemnya dapat kita lihat pada gambar 5, yang menunjukkan bahwa jika mobil mengalami gangguan permukaan jalan setinggi $10 \mathrm{~cm}$ (garis biru pada gambar 5), badan mobil akan mengalami perubahan ketinggian maksimal sebesar 1,8 cm (garis kuning pada gambar 5). Dengan melihat nilai yang dicapai dalam peredaman yang dilakukan oleh suspensi maka nilai tersebut mencapai $82 \%$ dari besarnya gangguan.

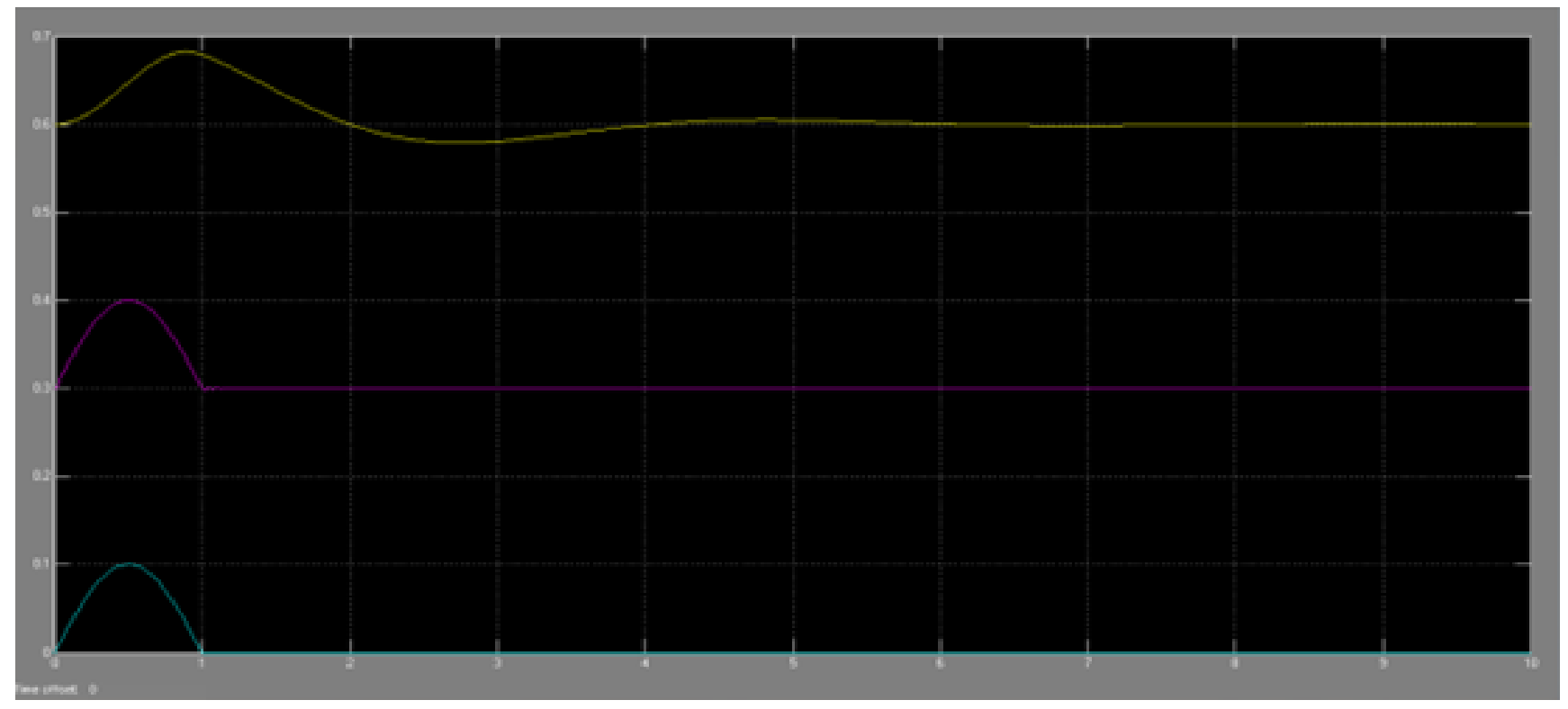

Gambar 4. Respon sistem suspensi tanpa sistem pengaturan dan gangguan gundukan jalan setinggi $10 \mathrm{~cm}$ 


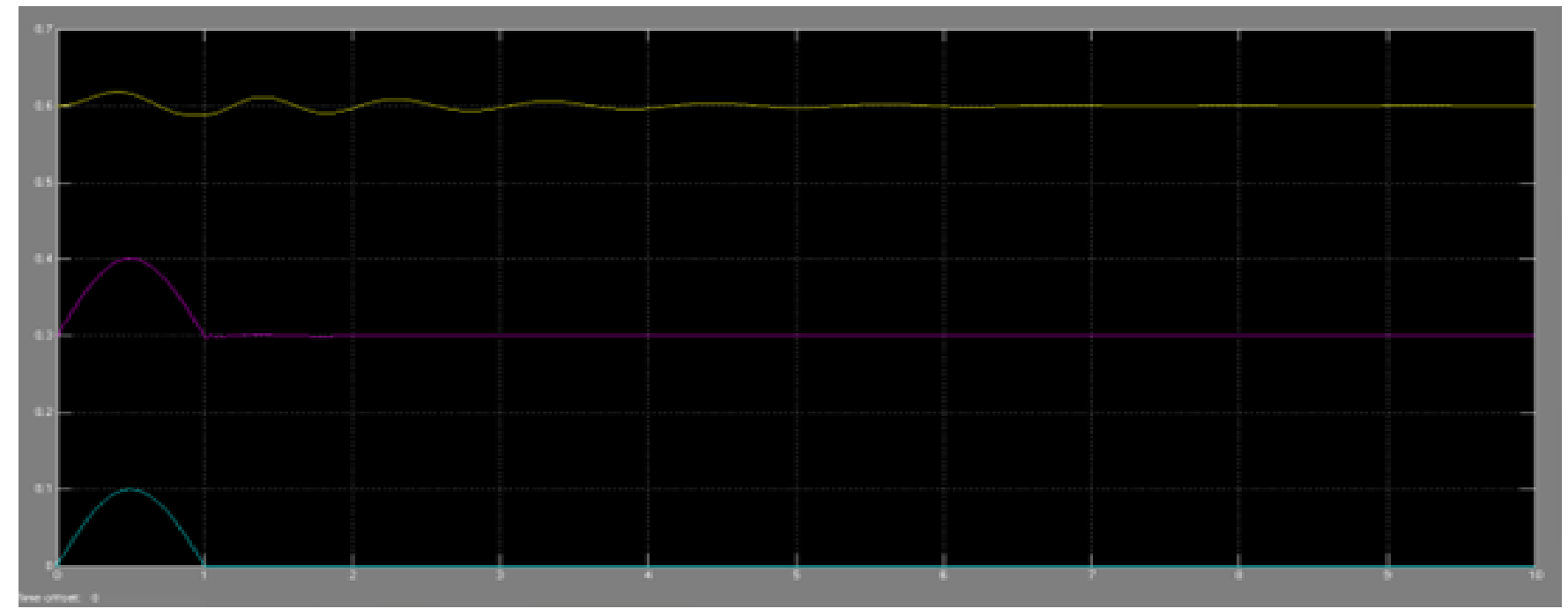

Gambar 5. Respon sistem suspensi dengan sistem pengaturan dan gangguan gundukan jalan setinggi $10 \mathrm{~cm}$

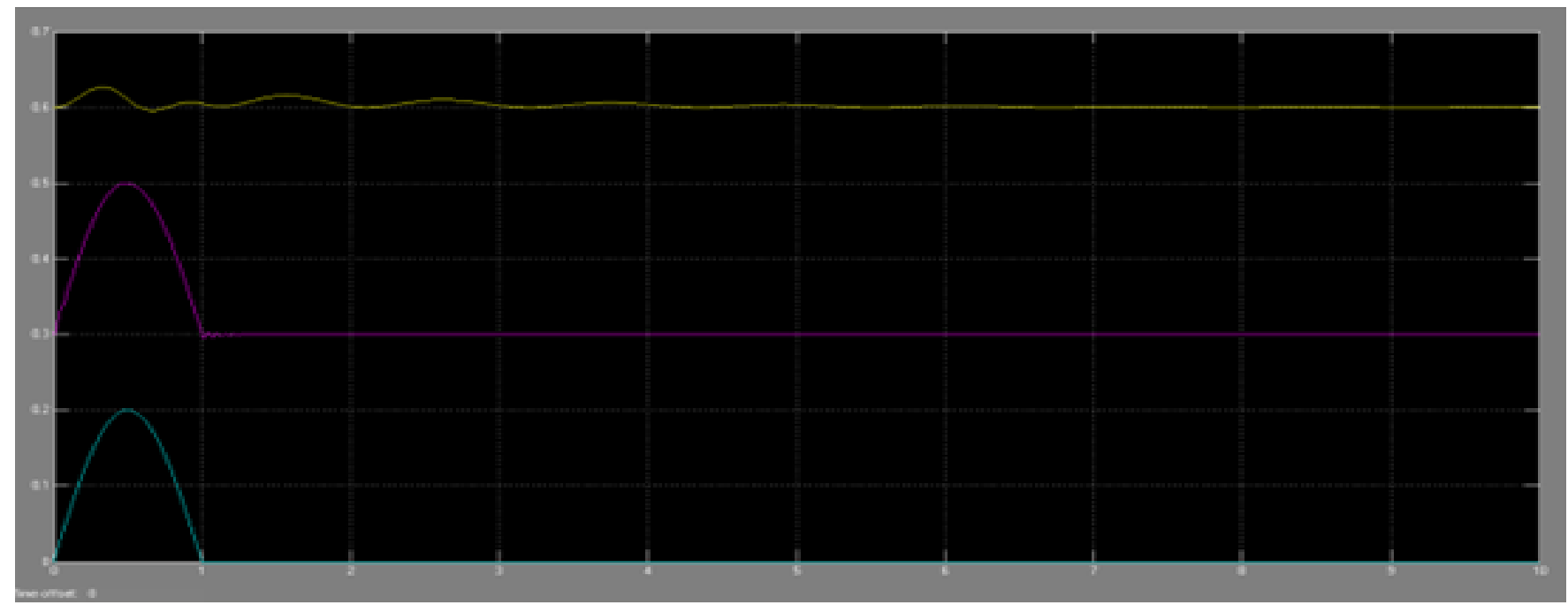

Gambar 6. Respon sistem suspensi tanpa sistem pengaturan dan gangguan gundukan jalan setinggi $20 \mathrm{~cm}$

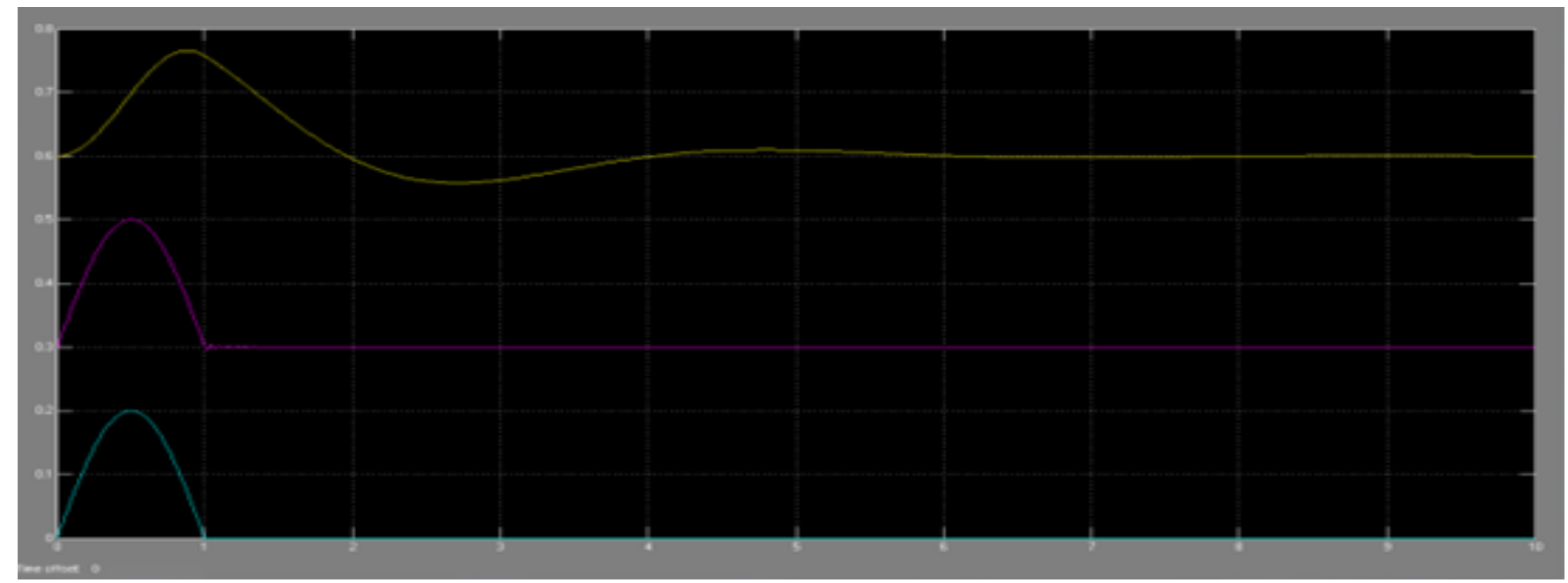

Gambar 7. Respon sistem suspensi dengan sistem pengaturan dan gangguan gundukan jalan setinggi $20 \mathrm{~cm}$ 
Pada simulasi selanjutnya dimasukkan gangguan berupa gundukan pada permukaan jalan setinggi $20 \mathrm{~cm}$. Gambar 6 menunjukkan respon sistem suspensi aktif tanpa sistem pengaturan yang diberi gangguan gundukan setinggi $20 \mathrm{~cm}$ (garis biru pada gambar 6), badan mobil mengalami perubahan ketinggian karena gangguan jalan setinggi $16 \mathrm{~cm}$ (garis kuning pada gambar 6). Sistem suspensi yang diatur oleh sistem pengaturan Neuro-Fuzzy Adaptif PID control menunjukkan respon sistem ditunjukkan pada gambar 7 . Gangguan gundukan jalan setinggi $20 \mathrm{~cm}$ (garis biru pada gambar 7) tidak terlalu mempengaruhi perubahan ketinggian pada badan mobil yang hanya berubah ketinggian sebesar $2,7 \mathrm{~cm}$ atau sekitar 13,5\% dari besarnya gangguan perubahan ketinggian permukaan jalan. Dengan adanya hasil ini dapat terlihat bahwa sistem pengaturan NeuroFuzzy Adaptif PID Control secara baik mengatur suspensi aktif Quarter-car sehingga dapat meredam perpindahan ketinggian badan mobil akibat gangguan jalan sebesar lebih dari $80 \%$ dari besarnya gangguan jalan yang ada.

\section{KESIMPULAN}

Metode pengaturan Neuro-Fuzzy Adaptif PID Control sangat efektif dalam mengatur suspensi aktif quarter-car dengan gangguan berupa gundukan pada permukaan jalan.

Pada gangguan gundukan jalan setinggi $10 \mathrm{~cm}$ suspensi aktif yang diatur dengan Neuro-Fuzzy Adaptif PID mampu meredam sebesar $82 \%$ gangguan sehingga badan mobil hanya mengalami perubahan ketinggian akibat gundukan jalan sebesar $1,8 \mathrm{~cm}$.

Pada gangguan gundukan jalan setinggi $20 \mathrm{~cm}$ suspensi aktif yang diatur dengan Neuro-Fuzzy Adaptif PID mampu meredam gangguan sebesar $86,5 \%$ sehingga badan mobil hanya mengalami perubahan ketinggian akibat gundukan jalan sebesar $2,7 \mathrm{~cm}$.

Performansi ini menunjukkan bahwa Suspensi Aktif Quarter-car dengan Pengaturan Neuro-Fuzzy Adaptif PID
Control dapat meredam gangguan gundukan jalan di atas $80 \%$ sehingga badan mobil hanya berpindah ketinggiannya lebih kecil dari $20 \%$ dibandingkan dengan gangguan jalan.

\section{DAFTAR ACUAN}

[1] H. Du and N. Zhang, "Hळ control of active vehicle suspensions with actuator time delay," J. Sound Vib., vol. 301, no. 1-2, pp. 236-252, Mar. 2007, doi: 10.1016/j.jsv.2006.09.022.

[2] M. Salem and A. Aly, "Fuzzy control of a quarter-car suspension system,” Jan. 2000.

[3] G. Priyandoko, M. Mailah, and H. Jamaluddin, "Vehicle active suspension system using skyhook adaptive neuro active force control," Mech. Syst. Signal Process., vol. 23 no. 3, pp. 855-868, Apr. 2009, doi:

10.1016/J.YMSSP.2008.07.014

[4] A. R. A. Ferdinandus, A. T. Nugraha, and J. Jamaaluddin, "Setting Neuro-Fuzzy PID Control in Plant Nonlinear Active Suspension," J. Phys. Conf. Ser., vol. 1114, no. 1, 2018, doi: 10.1088/1742-6596/1114/1/012063.

[5] S. F. Youness and E. C. Lobusov, "Networked Control for Active Suspension System," Procedia Comput. Sci., vol. 150, pp. 123-130, Jan. 2019, doi: 10.1016/J.PROCS.2019.02.025.

[6] S. Ikenaga, F. L. Lewis, J. Campos, and L. Davis, “Active suspension control of ground vehicle based on a fullvehicle model," in Proceedings of the 2000 American Control Conference. ACC (IEEE Cat. No.00CH36334), 2000, vol. 6, pp. 4019-4024 vol.6, doi: 10.1109/ACC.2000.876977.

[7] Y. Md Sam and J. Osman, "Modeling and control of the active suspension system using proportional integral sliding mode approach," Asian J. Control, vol. 7, pp. 9198, Jun. 2005, doi: 10.1111/j.1934-6093.2005.tb00378.x. 